\title{
ADVANCED PURIFICATION OF INDUSTRIAL QUARTZ USING CALCINATION PRETREATMENT COMBINED WITH ULTRASOUND-ASSISTED LEACHING
}

\author{
Changqiao YANG, Suqin LI*, Jiaxing BAI and Shuaishuai HAN
}

School of Metallurgical and Ecological Engineering, University of Science and Technology Beijing, Beijing, 100083, China

*Corresponding author's e-mail: lisuqin@metall.ustb.edu.cn

\begin{tabular}{l} 
ARTICLE INFO \\
\hline Article history: \\
Received 25 February 2018 \\
Accepted 20 June 2018 \\
Available online 26 June 2018
\end{tabular}

Keywords:

High purity quartz

Iron removal

Calcination pretreatment

Ultrasound-assisted leaching

Gas-liquid inclusions

\begin{abstract}
Purification of quartz using an environment-friendly method is important in the contaminants removal. This paper presents advanced method based on calcination pretreatment combined with ultrasound-assisted leaching, for removing iron impurities from industrial quartz. The solvent used is a mixture comprised by diluted hydrochloric acid and oxalic acid. The effects of experimental parameters were investigated and the purification mechanism was discussed using particle size analyzer, scanning electron microscope and polarized light microscope. $\mathrm{SiO}_{2}$ content of concentrate could be increased from $99.6828 \%$ to $99.9047 \%$, which achieved $3 \mathrm{~N}$ level high purity quartz, and $\mathrm{Fe}_{2} \mathrm{O}_{3}$ content reduced from $0.0857 \%$ to $0.0223 \%$, under the optimal conditions, i.e., calcination temperature of $900{ }^{\circ} \mathrm{C}$, holding time of $2 \mathrm{~h}$, oxalic acid concentration of $10 \mathrm{~g} / \mathrm{L}$, hydrochloric acid concentration of $5 \%$, liquid solid ratio of 5 , leaching temperature of $60{ }^{\circ} \mathrm{C}$, ultrasound power of $400 \mathrm{~W}$ and treatment time of $30 \mathrm{~min}$. Compared to conventional method, the proposed method significantly accelerates the leaching process and increases the iron removal rate. At the same time, the method also can remove gas-liquid inclusions.
\end{abstract}

\section{INTRODUCTION}

High grade quartz is an important non-metallic high-tech raw material, which is widely used in microelectronics, large scale integrated circuits, optical fibers, solar cells, electro-magnetic materials, aerospace, military and other industry sectors (Tuncuk and Akcil, 2016). Currently, whether at home or aboard natural crystal stones are used as raw materials, which after extensive purification allow obtaining high purity quartz products. However, the natural crystal stones are every time more scarce and by this, they turn to be more expensive. Therefore, seeking low price, high efficiency, environmentfriendly quartz purification technologies plays a strategic role in this matter. Among all impurities present in quartz, iron is the most difficult to remove. A presence of iron compounds leads to an unacceptable coloring of the final product (Zhang et al., 2012). Iron impurities embedded in the quartz particle or attached to the quartz surface, or wrapped in the gas-liquid inclusion are difficult to be removed. Nowadays, two main chemical acid leaching iron removing methods exist. The conventional leaching method involves the use of hydrofluoric acid mixed in different concentrations with strong mineral acid (i.e. $\mathrm{HCl}, \mathrm{H}_{2} \mathrm{SO}_{4}, \mathrm{HNO}_{3}$ ) (Tuncuk and Akcil, 2014). For example, Santos et al. (2015) demonstrated the use of dilute $\mathrm{HCl}+\mathrm{HF}$ to treat quartz lumps. A commercial purity quartz powder obtained contained $\mathrm{Fe}, \mathrm{Al}$ impurities with concentration below $15 \mathrm{ppm}$ and $50 \mathrm{ppm}$, respectively. One of the biggest advantages of this method is a high leaching efficiency. However, since silica is soluble in HF, some losses of product are inevitable. Additionally, $\mathrm{HF}$ is one of such chemicals which are harmful either to the environment or to the process operator. Because of these limitations, more environment-friendly HF-free methods characterized by loss-free of the target product and less acidic lixivium have been developed. One of the major limitations of these new methods is a processing time, which is prolonged and that they show a low and still unsatisfactory efficiency of iron removal. Therefore, harmless and highly efficient acid leaching processes are required. The research performed in recent years depicted a new trend in this matter. It is characterized by the use of weak organic acids (such as oxalic acid, citric acid, ascorbic acid) as substitute of mineral acid in contaminant treatments (Li et al., 2010; Lee et al., 2007; Li et al., 2016). The application of oxalic acid caused wide attention (Salmimies et al., 2012). For example, Vegliò et al. (1999) showed that $20-30 \%$ of iron was removed when $3 \mathrm{~g} / \mathrm{L}$ oxalic acid at $80^{\circ} \mathrm{C}$ was used. In this case the average size of the quartz sand was $71 \mu \mathrm{m}$. Huang et al. (2013) registered an iron removal rate of $37.5 \%$ by oxalic acid, at the optimal concentration of $6 \mathrm{~g} / \mathrm{L}$. Taxiarchou et al. (1997) obtained a $40 \%$ of iron removal rate with the oxalic acid concentration of 
Table 1 The chemical composition of original samples (\%). ${ }^{\mathrm{a}}$

\begin{tabular}{lccccccc}
\hline Components & $\mathrm{SiO}_{2}$ & $\mathrm{Al}_{2} \mathrm{O}_{3}$ & $\mathrm{Fe}_{2} \mathrm{O}_{3}$ & $\mathrm{CaO}$ & $\mathrm{Na}_{2} \mathrm{O}$ & $\mathrm{K}_{2} \mathrm{O}$ & $\mathrm{MgO}$ \\
\hline Amount & 99.5828 & 0.1158 & 0.0857 & 0.0422 & 0.0387 & 0.0355 & 0.0327 \\
\hline
\end{tabular}

${ }^{\mathrm{a}}$ The oxides of less than $0.03 \%$ are not shown.

$4.5 \mathrm{~g} / \mathrm{L}$ at $90-100{ }^{\circ} \mathrm{C}$ with the particle size of $265 \mu \mathrm{m}$. These examples clearly show that the efficiency of iron impurities using oxalic acid alone is still below that expected. Therefore, a mixture of oxalic acid and mineral acid, used in industrial practice for iron removal was employed. Vegliò et al. (1998) showed an advance of this approach and managed to improve the iron extraction rate to $35-45 \%$ using $3 \mathrm{~kg} / \mathrm{t}$ oxalic acid and $2 \mathrm{~kg} / \mathrm{t}$ sulphuric acid at $90{ }^{\circ} \mathrm{C}$ for $4-5 \mathrm{~h}$. This shows more than $50 \%$ improvement when compared to oxalic acid alone. Nevertheless, these numbers are still unsatisfactory.

The purpose of this work is to seek a novel and efficient environment-friendly solvent to remove impurities without reducing the final product yield. For this purpose, the calcination pretreatment combined with ultrasound-assisted leaching to remove iron impurities was employed and compared to regular method. Additionally, optimization of operating conditions has been investigated too.

\section{MATERIALS AND METHODS}

\subsection{RAW MATERIALS AND REAGENTS}

The quartz samples were provided by Lianyungang Xinhai Quartz Products Co., Ltd, which locates in Lianyungang city of Jiangsu province, China. The chemical composition of sample was determined by XRF (Axios mAX, Netherlands PANalytical) and presented in Table 1. All chemical reagents used were of analytical reagent grade which were produced by Sinopharm Group Chemical Reagent Co., Ltd., China. And deionized water (labo ratory production) was used throughout the work.

\subsection{EXPERIMENTAL PROCEDURE}

\subsubsection{QUARTZ SANDS CALCINATION PRETREATMENT}

The known amount of quartz sands were placed in a corundum crucible and placed in the box furnace to be thermally treated at predetermined temperature and time. Next, for process quenching, such treated samples were poured into water. Finally, the samples were filtered and dried.

\subsubsection{CONVENTIONAL LEACHING EXPERIMENTS}

The leaching agent was prepared by dissolving known amounts of oxalic and hydrochloric acids in the deionized water. The prepared leaching agent was heated up to a desired temperature and $20 \mathrm{~g}$ dry sands were immediately added into the hot liquid under continuous stirring. To prevent evaporation, the glass extraction vessel was closed throughout the leaching experiment. When the reaction was completed, the filtrate was drained and the residue was taken out. The residue was washed in the deionized water up to neutral $\mathrm{pH}$. Then it was filtered onto the filter paper and dried for subsequent composition analysis.

\subsubsection{ULTRASOUND-ASSISTED ACID LEACHING EXPERIMENTS}

The ultrasonic-assisted experiments were conducted according to the same procedure as described above. The only difference was that an ultrasound probe was immersed into the liquid to be extracted in the glass extraction vessel. Different input powers and treatment times were examined. After the desired extraction time, the same washing procedure was implemented as presented in Section 2.2.2.

All experiments were carried out at least in duplicate and the mean values were taken as the final results. A schematic diagram of the experimental setup is shown in Figure 1.

\subsection{EVALUATION AND CHARACTERIZATION}

The iron content of the quartz sands was examined by ICP-OES (Varian 715-ES, USA). The iron removal rate was calculated using the following equation:

$\eta=\left(1-\frac{\theta}{\alpha}\right) \times 100 \%$

Where $\eta$ is the iron removal rate, $\theta$ is the amount of iron in leached solid samples, $\alpha$ is the amount of iron in ore samples.

The particle size and size distribution of the samples were determined by laser light scattering method (Mastersizer, 2000, Malvern, UK). The morphologies of samples were observed using scanning electron microscopy (ZEISS EVO 18 Special Edition, Germany Carl Zeiss Jena) and polarized light microscope (OLYMPUSB $\times 51 \mathrm{TF}$, Japan).

\section{RESULTS AND DISCUSSION}

\subsection{EFFECT OF MIXED ACID CONCENTRATION ON IRON REMOVAL EFFICIENCY}

The influence of oxalic acid (OA) and hydrochloric acid $(\mathrm{HCl})$ concentrations on iron removal in solutions containing liquid solid ratio (L/S) of 5 , reaction temperature of $60^{\circ} \mathrm{C}$ and leaching time of $8 \mathrm{~h}$ were studied. The results are shown in Figure 2. According to this figure, an increase in the $\mathrm{OA}$ concentration affects positively the iron removal rate. This can be attributed to the fact that OA reacts with $\mathrm{Fe}$, thus high $\mathrm{OA}$ concentration should favor $\mathrm{Fe}$ 


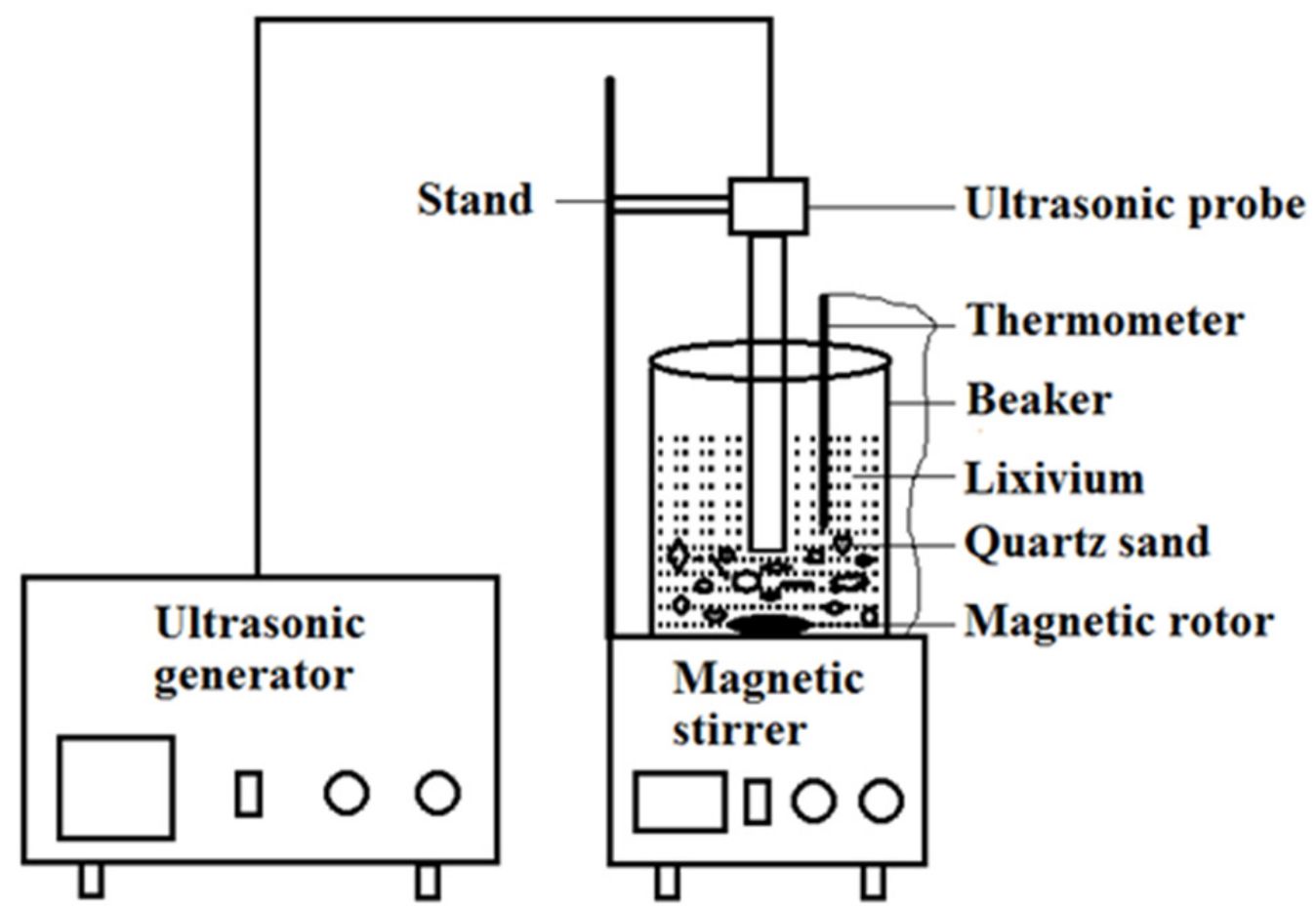

Fig. 1 Schematic diagram of the experimental set-up.

removal. However, when the OA concentration exceeds a certain critical value, further increase in OA concentration does not contribute to the enhancement in iron removal rate that it visible in Figure 2 as plateau or even as a decay. The maximum iron removal rate varies depending on the $\mathrm{HCl}$ concentration. As it can be observed, $1 \% \mathrm{HCl}$ shows the lowest $\mathrm{Fe}$ removal efficiency. For higher $\mathrm{HCl}$ concentrations, the $\mathrm{Fe}$ removal depends on the synergistic effect of $\mathrm{HCl}$ and $\mathrm{OA}$. An increase in $\mathrm{HCl}$ concentration enhances the Fe removal, especially observable at low OA concentrations. When the OA concentration is higher than $4 \mathrm{~g} / \mathrm{L}$, iron removal rate at $15 \% \mathrm{HCl}$ is lower than that for $10 \% \mathrm{HCl}$, whereas for concentrations above $8 \mathrm{~g} / \mathrm{L}$ of $\mathrm{OA}$, the highest $\mathrm{Fe}$ removal is observed for $5 \% \mathrm{HCl}$ followed by 10 and $15 \%$. This trend can be attributed to the fact that in the aqueous system $\mathrm{OA}$ reacts according to the following ionization reaction (Panias et al., 1996):

$\mathrm{Fe}_{2} \mathrm{O}_{3}+6 \mathrm{H}_{2} \mathrm{C}_{2} \mathrm{O}_{4}=2 \mathrm{Fe}\left(\mathrm{C}_{2} \mathrm{O}_{4}\right)_{3}{ }^{3-}+6 \mathrm{H}^{+}+3 \mathrm{H}_{2} \mathrm{O}$

$2 \mathrm{Fe}\left(\mathrm{C}_{2} \mathrm{O}_{4}\right)_{3}{ }^{3-}+6 \mathrm{H}^{+}+4 \mathrm{H}_{2} \mathrm{O}=$

$=2 \mathrm{FeC}_{2} \mathrm{O}_{4} \cdot 2 \mathrm{H}_{2} \mathrm{O}+3 \mathrm{H}_{2} \mathrm{C}_{2} \mathrm{O}_{4}+2 \mathrm{CO}_{2}$

$\mathrm{Fe}_{2} \mathrm{O}_{3}+3 \mathrm{H}_{2} \mathrm{C}_{2} \mathrm{O}_{4}+\mathrm{H}_{2} \mathrm{O}=2 \mathrm{FeC}_{2} \mathrm{O}_{4} \cdot 2 \mathrm{H}_{2} \mathrm{O}+2 \mathrm{CO}_{2}$

$\mathrm{H}_{2} \mathrm{C}_{2} \mathrm{O}_{4}=\mathrm{H}^{+}+\mathrm{HC}_{2} \mathrm{O}_{4}$

$\mathrm{HC}_{2} \mathrm{O}_{4}{ }^{-}=\mathrm{H}^{+}+\mathrm{C}_{2} \mathrm{O}_{4}{ }^{2-}$

When $\mathrm{OA}$ is in mixture with $\mathrm{HCl}$, for low $\mathrm{HCl}$ concentration $\mathrm{OA}$ is mainly present in $\mathrm{HC}_{2} \mathrm{O}_{4}^{-}$form. Hence dissociated $\mathrm{OA}$ has higher ability to complex iron ion and consequently promotes its removal. However, when $\mathrm{HCl}$ concentration is high, the $\mathrm{H}^{+}$in the solution will suppress OA dissociation, OA is mainly present in the molecular form, which is not effective in iron complex reaction. When the $\mathrm{HCl}$ concentration is $10 \%$ and $15 \%$, a solution contains a high $\mathrm{H}^{+}$content that inhibits $\mathrm{OA}$ dissociation and hampers the iron removal even for high OA concentrations. For the $\mathrm{HCl}$ concentration between $1 \%$ and $5 \%, \mathrm{H}^{+}$in the solution is low and at these concentrations, an additional amount of OA promotes its dissociation and complexation of $\mathrm{Fe}^{3+}$ that improves the leaching efficiency. This effect is observed until the OA concentration reaches $10 \mathrm{~g} / \mathrm{L}$. Above $10 \mathrm{~g} / \mathrm{L}$ of OA, OA inhibits its own dissociation. As it was stated above, in the entire range of the $\mathrm{OA}$ concentrations studied, the iron removal rate at $1 \% \mathrm{HCl}$ is lower than at $5 \% \mathrm{HCl}$. The reason for this might be that $1 \% \mathrm{HCl}$ concentration is too low to promote $\mathrm{OA}$ dissociation and the complexity of iron impurities is insufficient. Thus it is difficult to achieve a sufficient dissolution of iron impurities and subsequent removal. Considering all abovementioned aspects, $5 \% \mathrm{HCl}$ and $10 \mathrm{~g} / \mathrm{L} \mathrm{OA}$ were selected as the optimal concentrations with the iron removal rate of $53 \%$.

\subsection{EFFECT OF EXTRACTION TIME ON IRON REMOVAL EFFICIENCY}

The influence of extraction time on the iron removal efficiency is presented in Figure 3. A careful analysis of this figure allows stating that longer time promotes iron removal gradually until a certain level is achieved. Above this level there is no further 


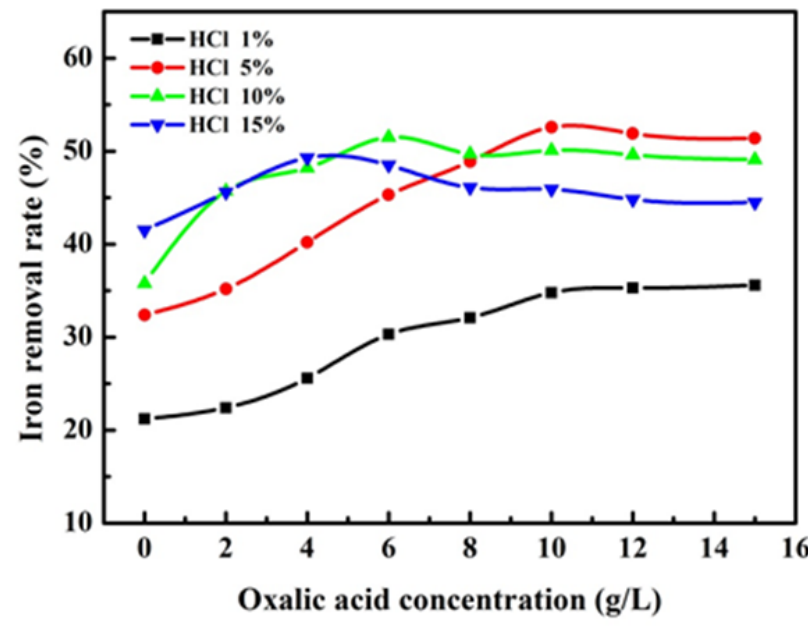

Fig. 2 The effect of oxalic acid concentration on iron removal rate (Acid leaching conditions leaching temperature: $60{ }^{\circ} \mathrm{C}$, extraction time: $8 \mathrm{~h}, \mathrm{~L} / \mathrm{S}: 5$, stirring speed: $500 \mathrm{rpm}$ ).

enrichment in iron removal. It can be concluded that longer time allows more extensive dissolution of iron impurities, making them available for complexing and removal. Once the iron dissolution equilibrium is obtained, no further increase in dissolution of iron, the maximum removal rate can be obtained. At this condition, the extraction temperature higher has a positive effect on iron removal. From the leaching dynamics point of view, the extraction temperature plays an important role in the chemical reaction rate of the leaching process. An increase in extraction temperature makes that the energy of the mineral particles rises, thus the leaching rate accelerates and consequently the dissolution of iron is advanced and balanced quickly. For example, time needed to reach equilibrium was shortened by 2 hours from $8 \mathrm{~h}$ at $50{ }^{\circ} \mathrm{C}$ to $6 \mathrm{~h}$ at $70{ }^{\circ} \mathrm{C}$. However, after reaching equilibrium, an increase in temperature does not improve the iron removal efficiency. For example, when the process was carried out for $8 \mathrm{~h}$, the iron removal rate at $80{ }^{\circ} \mathrm{C}$ was lower than that at $60{ }^{\circ} \mathrm{C}$. The reason for this might be that at higher temperature $\mathrm{HCl}$ undergoes more extended evaporation and the actual acid concentration decreases contributing to lower dissolution of iron impurities. Therefore, seeking leaching efficiency and taking into consideration the energy requirements, $60^{\circ} \mathrm{C}$ and $8 \mathrm{~h}$ were considered as the best conditions at which the iron removal rate reached $53 \%$.

\subsection{EFFECT OF LIQUID SOLID RATIO ON IRON REMOVAL EFFICIENCY}

The effect of liquid solid ratio on the iron removal was investigated in the range of L/S of 3-8 and the results are shown in Figure 4. The iron removal rate increases with increasing $\mathrm{L} / \mathrm{S}$ until it reaches 6 , then slightly decreases with further increase in L/S. In each experiment performed with the same quality of quartz sands, the increase in the $\mathrm{L} / \mathrm{S}$

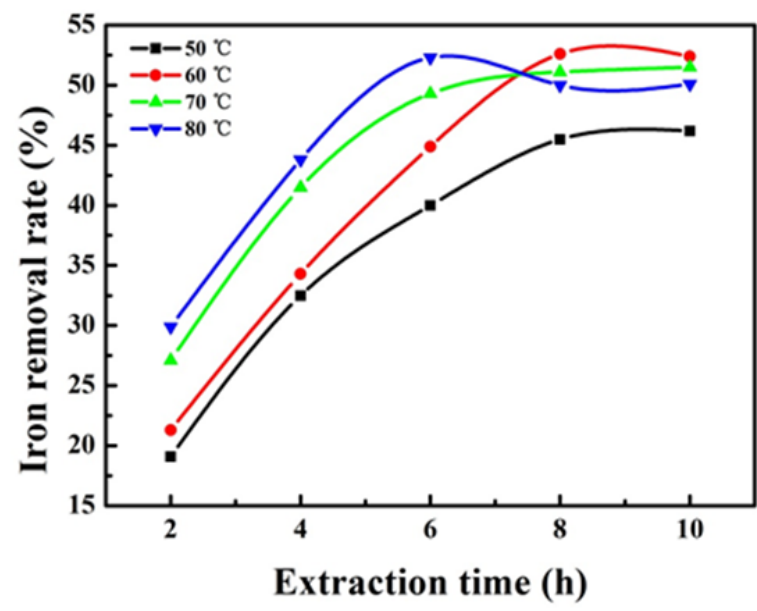

Fig. 3 The effect of extraction time on iron removal rate (Acid leaching conditions - OA concentration: $10 \mathrm{~g} / \mathrm{L}, \mathrm{HCl}$ concentration: $5 \%$, L/S: 5 , stirring speed: $500 \mathrm{rpm}$ ).

contributes to the increase in the amount of acid solution. Consequently, this improves the fluidity of the slurry. Hence, the mass transfer limitations were avoided contributing to the reaction rate improvements. With an increase in $\mathrm{L} / \mathrm{S}$ the viscosity of the slurry is lower and the diffusion rate becomes larger. This contributes to higher leaching rate. However, an increase in the L/S not only makes the waste more acidic, but also increases the volume of the leaching mixture. This means an additional capital expenditure, which is a negative effect. An increase in L/S from 5 to 6 improves the iron removal rate from $54 \%$ to $55 \%$, only increased by $1 \%$. Therefore, from the economic point of view, the L/S of 5 is more suitable choice.

\subsection{EFFECT OF ULTRASOUND TREATMENT ON IRON REMOVAL EFFICIENCY}

The influence of ultrasound input power on the iron removal was performed with 100, 200, 300, 400 and $500 \mathrm{~W}$. The iron removal rate increases along the increase in the ultrasound power as shown in Figure 5. However, this increase is visible up to $400 \mathrm{~W}$ and further rise of ultrasound power above that one does not improve the iron removal rate that is $64 \%$. When ultrasound waves pass through the liquid, alternating tensile stress will be put on liquid particles, generating cavitation bubbles that will collapse during the compression process of the liquid. The collapse will cause huge pressure change that leads to severe local temperature rise and associated energy release. Under the impact of the generated local high temperature and strong micro-jet, the impurities attached and embedded on the surfaces of quartz particles will fall off into the mixed acid solution, resulting in many micro-pits on the surface (Du et al., 2010). The pit become deeper and larger, so the mixed acid solution can penetrate easier into the quartz particles, improving the iron impurities removal by a formation 


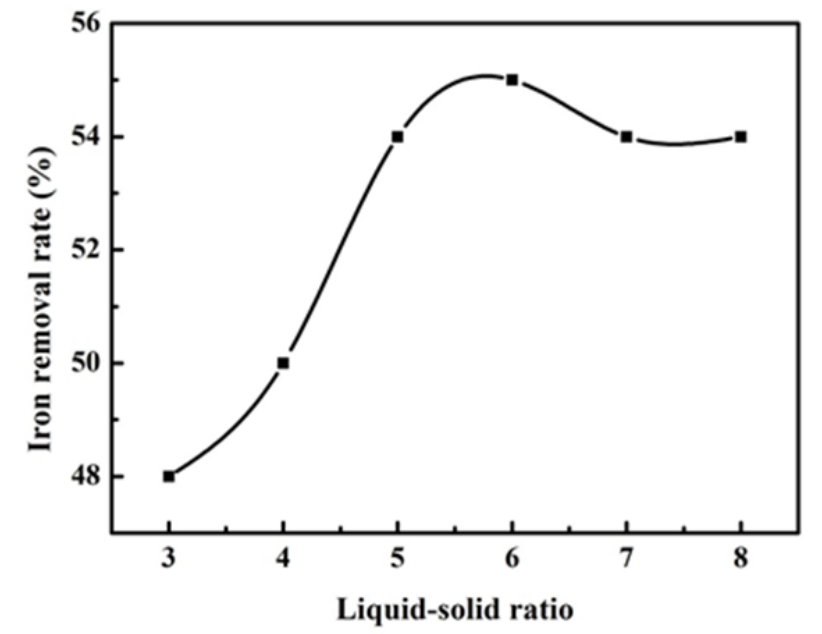

Fig. 4 The effect of liquid solid ratio on iron removal rate (Acid leaching conditions - OA concentration: $10 \mathrm{~g} / \mathrm{L}, \mathrm{HCl}$ concentration: $5 \%$, leaching temperature: $60{ }^{\circ} \mathrm{C}$, extraction time: $8 \mathrm{~h}$, stirring speed: $500 \mathrm{rpm}$ ).

of "micro-pit" in the inner part. Under the combined action of ultrasound and acid leaching, the quartz particles are more porous and even broken, so that the internal iron impurities are exposed to acid solution and ultrasound treatment enhances the kinetic conditions of the iron removal (Zhao et al., 2007; Farmer et al., 2000). Considering the above discussed aspect, a $400 \mathrm{~W}$ of ultrasound power input was selected.

The effect of ultrasound treatment time on iron removal was examined in the range of 10-50 min and the results are given in Figure 6. According to Figure 6, the iron removal rate increases with increasing ultrasound treatment time until $30 \mathrm{~min}$. For longer treatment time no visible improvement can be observed. As it can be seen in Figures 3 and 6 , the iron removal rate is much higher at ultrasound treatment than conventional leaching. It increases from $53 \%$ of $8 \mathrm{~h}$ for conventional leaching to $64 \%$ of $30 \mathrm{~min}$ for ultrasound treatment. A possible explanation for the phenomenon is that the cavitation effect produced by sonication improves the kinetic conditions of the reaction. Ultrasound treatment makes the quartz particles smaller, increases the liquid solid interface and improves the surface diffusion rate of reactants. Thus, it speeds up the iron removal. However, the iron removal rate is almost no increased after $30 \mathrm{~min}$; consequently a $30 \mathrm{~min}$ was selected as the optimal treatment time.

\subsection{EFFECT OF CALCINATION PRETREATMENT ON IRON REMOVAL EFFICIENCY}

The influence of calcination temperature on the iron removal was studied in the temperature range of $500-1000{ }^{\circ} \mathrm{C}$ with holding time $2 \mathrm{~h}$. The results are shown in Figure 7. According to Figure 7, the iron removal rate increases from $65 \%$ at $500{ }^{\circ} \mathrm{C}$ to $75 \%$ at

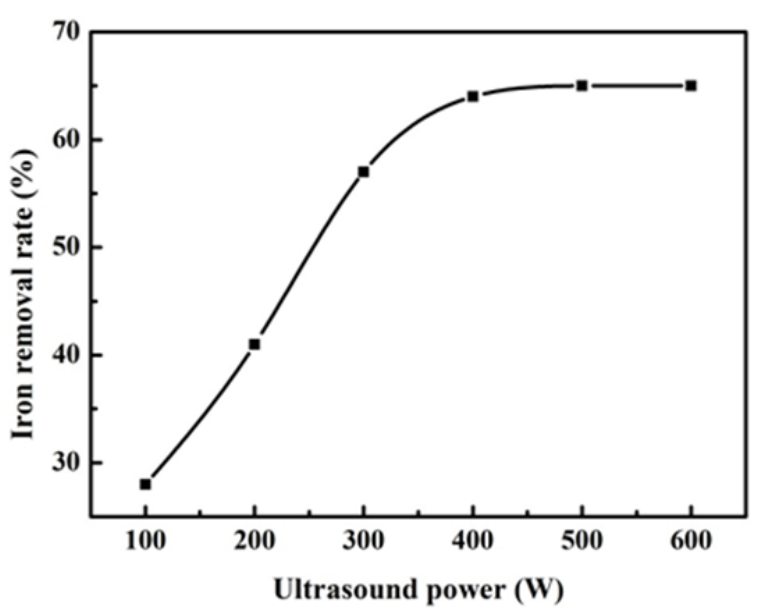

Fig. 5 The effect of ultrasound power on iron removal rate (Acid leaching conditions - OA concentration: $10 \mathrm{~g} / \mathrm{L}, \mathrm{HCl}$ concentration: $5 \%$, leaching temperature: $60{ }^{\circ} \mathrm{C}, \mathrm{L} / \mathrm{S}: 5$, stirring speed: 0 . Ultrasound conditions time: $30 \mathrm{~min}$ ).

$1000{ }^{\circ} \mathrm{C}$. The observed behavior may be attributed to the crystal transformation. Quartz undergoes crystalline transition at $573{ }^{\circ} \mathrm{C}$ and $870{ }^{\circ} \mathrm{C}$ and both alters the volume of quartz. At $573{ }^{\circ} \mathrm{C} \alpha$-quartz form undergoes structural change to $\beta$-quartz with associated $5 \%$ volume expansion, whereas at $870{ }^{\circ} \mathrm{C}$ $\beta$-quartz form changes to $\beta$-squamous quartz with a $12 \%$ volume expansion (Balitsky et al., 1996; Moore, 1993). Due to a difference of the expansion rate between impurity and quartz, the rapid change in temperature can cause a large number of cracks at the junction of impurity and quartz matrix. Thus impurities embedded in the quartz become exposed and react with acid and the iron removal efficiency can be enhanced. High temperature is beneficial to the increase of the thermal stress during quenching process. At the same time, the increase in the thermal stress facilitates the acceleration of cracks in quartz and impurity. The internal iron impurities are exposed to acid solution and the iron removal rate are increased. However, as it can be seen in Figure 7, above the crystal transition temperature, a further increase in calcination temperature does not affect significantly the iron removal rate $\left(74 \%\right.$ at $900{ }^{\circ} \mathrm{C}$ and $75 \%$ at $1000{ }^{\circ} \mathrm{C}$ ), thus considering the energy consumption, $900{ }^{\circ} \mathrm{C}$ is more adequate than a $1000{ }^{\circ} \mathrm{C}$ higher temperature.

The influence of calcination holding time on iron removal was performed in the range of $0.5-2.5 \mathrm{~h}$. The results are shown in Figure 8. The iron removal rate increases rapidly with an extension of holding time. At $0.5 \mathrm{~h} 68 \%$ of iron removal was observed, while for 4-fold longer time $(2.0 \mathrm{~h})$ a $74 \%$ of iron removal was found. Further increase in time has no significant improvement in the iron removal efficiency. Therefore, the holding time of $2.0 \mathrm{~h}$ is opted as the best one. 


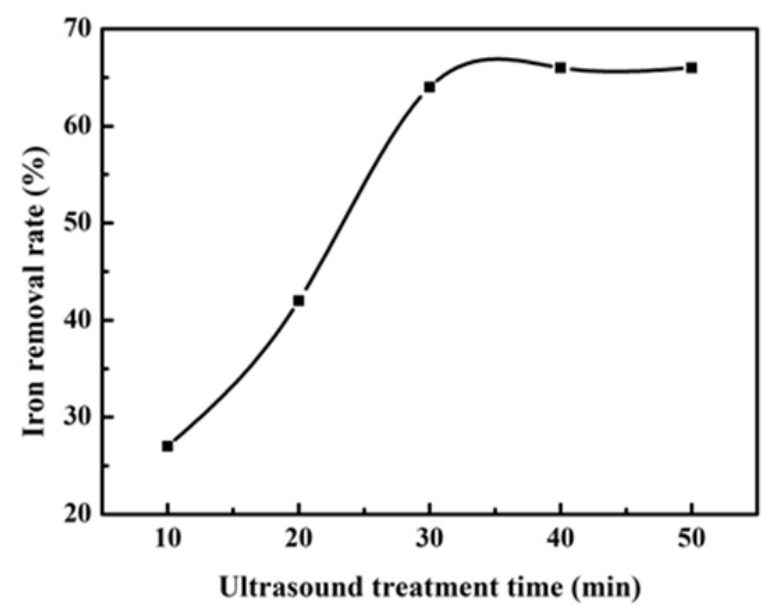

Fig. 6 The effect of ultrasound treatment time on iron removal rate (Acid leaching conditions OA concentration: $10 \mathrm{~g} / \mathrm{L}, \mathrm{HCl}$ concentration: $5 \%$, leaching temperature: $60{ }^{\circ} \mathrm{C}$, L/S: 5 , stirring speed: 0 . Ultrasound conditions power: $400 \mathrm{~W}$ ).

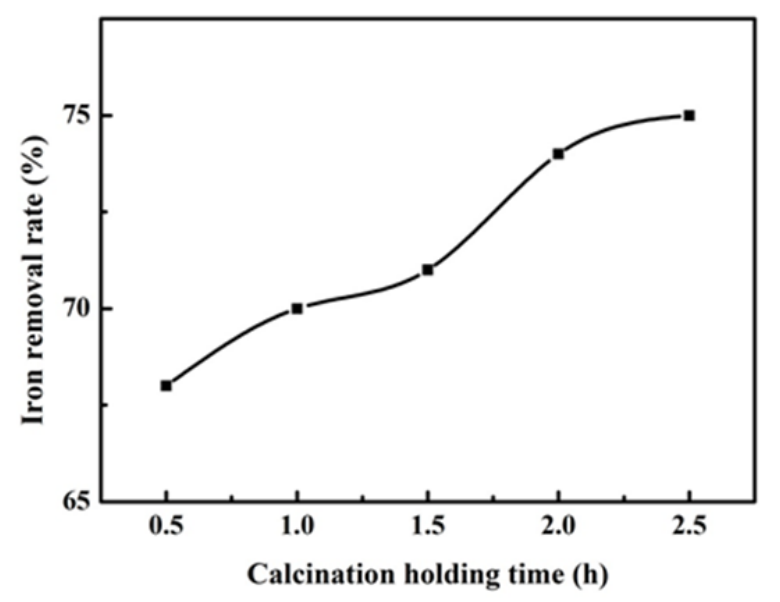

Fig. 8 The effect of calcination holding time on iron removal rate (Calcination conditionstemperature: $900{ }^{\circ} \mathrm{C}$. Acid leaching conditions - OA concentration: $10 \mathrm{~g} / \mathrm{L}, \mathrm{HCl}$ concentration: $5 \%$, temperature: $60{ }^{\circ} \mathrm{C}, \mathrm{L} / \mathrm{S}$ : 5, stirring speed: 0 . Ultrasound conditions power: $400 \mathrm{~W}$, time: $30 \mathrm{~min}$ ).

\subsection{COMPREHENSIVE CONDITION EXPERIMENT}

$3 \mathrm{~N}$ level high purity quartz product was obtained under the optimal parameters, i.e., a calcination temperature of $900{ }^{\circ} \mathrm{C}$, a calcination holding time of $2 \mathrm{~h}$, a oxalic acid concentration of $10 \mathrm{~g} / \mathrm{L}$, a hydrochloric acid concentration of $5 \%$, a extraction temperature of $60{ }^{\circ} \mathrm{C}$, a liquid solid ratio of 5 , a ultrasound power of $400 \mathrm{~W}$ and a ultrasound treatment time $30 \mathrm{~min}$. $\mathrm{SiO}_{2}$ content was increased from $99.6828 \%$ to $99.9047 \%, \mathrm{Fe}_{2} \mathrm{O}_{3}$ content reduced from $0.0857 \%$ to $0.0223 \%$, and a maximal iron removal rate up to $74 \%$. The chemical composition of concentrate is shown in Table 2.

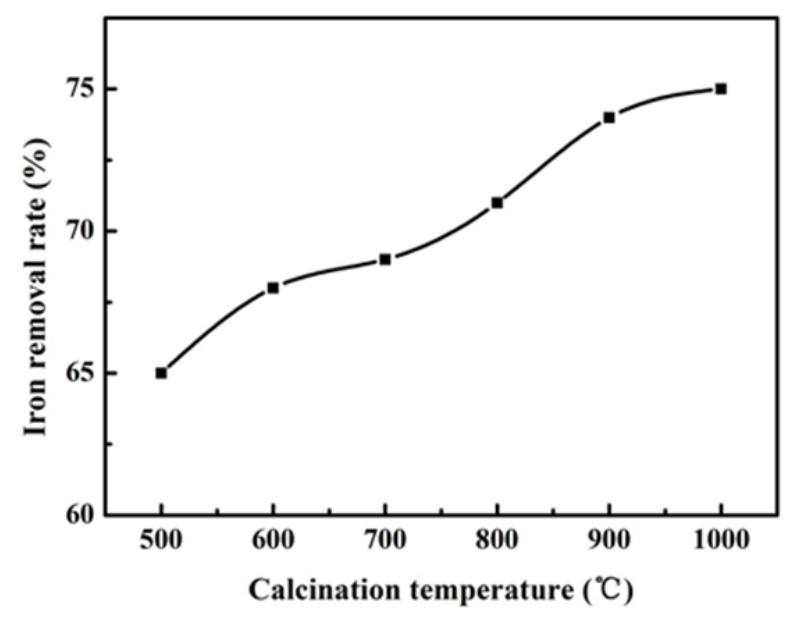

Fig. 7 The effect of calcination temperature on iron removal rate (Calcination conditions- holding time: $2 \mathrm{~h}$. Acid leaching conditions - OA concentration: $10 \mathrm{~g} / \mathrm{L}, \mathrm{HCl}$ concentration: $5 \%$, leaching temperature: $60{ }^{\circ} \mathrm{C}, \mathrm{L} / \mathrm{S}: 5$, stirring speed: 0. Ultrasound conditions power: $400 \mathrm{~W}$, time: $30 \mathrm{~min}$ ).

\subsection{EFFECT OF PURIFICATION PROCESS ON PARTICLE SIZE}

Figure 9 shows the sample particle size distribution analysis. The size of the initial quartz sands is between 150 and $350 \mu \mathrm{m}$ with the average particle size of $238 \mu \mathrm{m}$ (Fig.9A). Figure 9B shows the sample particle size distribution after conventional acid leaching with the average particle size of $234 \mu \mathrm{m}$, which is very similar to the initial sample because only $4 \mu \mathrm{m}$ decrease. The particle size distribution of the sample after ultrasound-assisted acid leaching is shown in Figure 9C and has an average particle size of $216 \mu \mathrm{m}$. A $22 \mu \mathrm{m}$ decrease in particle size can be observed in comparison to the initial one. This result is consistent with the analysis of section 3.4 , because the ultrasound cavitation and the combination of ultrasound and acid leaching promotes the quartz particles become more porous and even in some cases can break down. Figure 9D shows the particle size distribution of sample after calcination pretreatment and ultrasound-assisted acid leaching. The average particle size is $200 \mu \mathrm{m}$, which is $38 \mu \mathrm{m}$ lower than that of the initial one. This result is also in agreement with the results presented in section 3.5 because the volume changes caused by the crystal transformation lead to the particles size reduction by their breaking down.

\subsection{EFFECT OF PURIFICATION PROCESS ON MICROSTRUCTURE}

Figure 10 depicts SEM micrographs of samples. As it can be seen in Figure 10A, many small particles are adhered to or inlaid with the quartz particle surface and they can be considered as impurities. After the conventional acid leaching, a number of small particles adhered to the quartz particle surface is 
Table 2 The chemical composition of concentrate samples (\%).

\begin{tabular}{lccccccc}
\hline Components & $\mathrm{SiO}_{2}$ & $\mathrm{Al}_{2} \mathrm{O}_{3}$ & $\mathrm{Fe}_{2} \mathrm{O}_{3}$ & $\mathrm{CaO}$ & $\mathrm{Na}_{2} \mathrm{O}$ & $\mathrm{K}_{2} \mathrm{O}$ & $\mathrm{MgO}$ \\
\hline Amount & 99.9047 & 0.0810 & 0.0223 & 0.0106 & 0.0194 & 0.0189 & 0.0213 \\
\hline
\end{tabular}
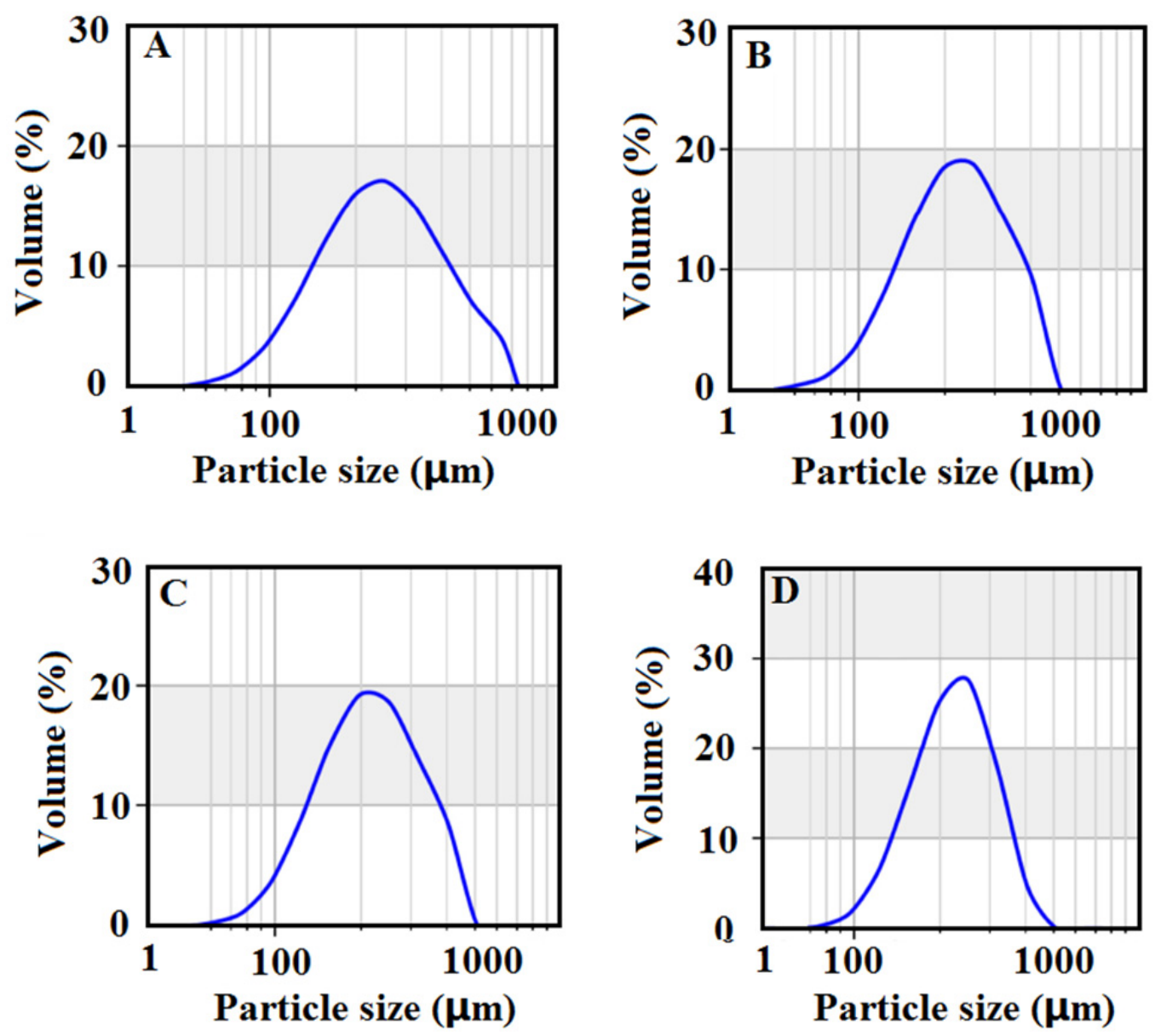

Fig. 9 Particle size distribution of (A) Original samples, (B) Leached solid samples, (C) Ultrasoundassisted leached solid samples and (D) Calcination pretreatment + ultrasound-assisted leached solid samples (Calcination conditions - temperature: $900{ }^{\circ} \mathrm{C}$, holding time: $2 \mathrm{~h}$. Acid leaching conditions - OA concentration: $10 \mathrm{~g} / \mathrm{L}, \mathrm{HCl}$ concentration: $5 \%$, temperature: $60{ }^{\circ} \mathrm{C}, \mathrm{L} / \mathrm{S}: 5$, stirring speed: $500 \mathrm{rpm}$. Ultrasound conditions - power: $400 \mathrm{~W}$, time: $30 \mathrm{~min}$ ).

lower. This may indicate that these impurities were partially dissolved in acid solution (Figure 10B). Figure 10C shows the ultrasound-assisted acid leaching sample in which almost all small particles disappeared. This is because a strong wave of ultrasound force can peel off impurities adhered on the quartz particle to the acid solution, which promoted further reactions. It can be observed that ultrasound treatment is more effective to remove iron impurities from the surface of quartz than conventional leaching. The maximum iron removal rate is $64 \%$, which means that the remaining iron impurities are difficult to be removed from the quartz sand lattice. The morphology of the quartz particle surface in Figure 10D (calcination pretreatment + ultrasound-assisted acid leaching testing sample) is similar to that in Figure 10C, but the iron removal rate increased to $74 \%$. This is due to rapid changes in temperature (calcination and water quenching treatment), which promoted the quartz particles disruption, so the internal impurities are exposed and reacted with the acid solution. Hence iron removal rate was improved.

\subsection{EFFECT OF PURIFICATION PROCESS ON GAS- LIQUID INCLUSIONS}

Figure 11 demonstrates polarized light microscope images of analyzed samples. The gasliquid inclusions inside quartz particle are smaller and mostly of micron-level (Fig. 11A). The conventional acid leaching can only remove impurities from the surface of particle, hence it is ineffective in the 

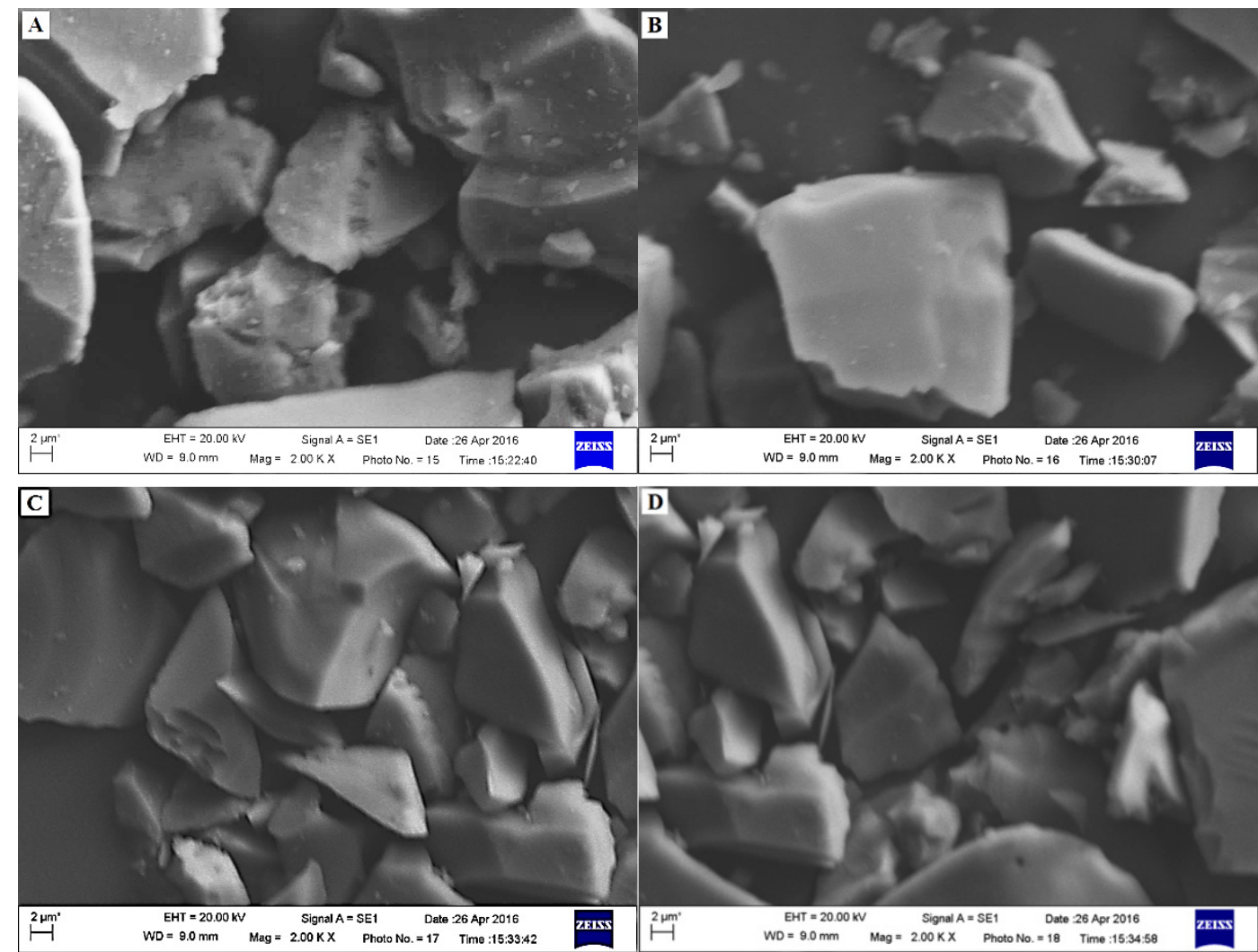

Fig. 10 SEM images of (A) Original samples, (B) Leached solid samples, (C) Ultrasound-assisted leached solid samples and (D) Calcination pretreatment + ultrasound-assisted leached solid samples (conditions of samples are same as those described in Figure 9).

removal of the gas-liquid inclusions as still some obvious inclusions can be seen in Figure 11B. It is apparent that the volume of the gas-liquid inclusions in the quartz particle after ultrasound-assisted acid leaching get smaller (Fig. 11C) and the ultrasound plays the bursting effect on the particles leading to the large volume of the gas-liquid inclusions to break. Relatively small gas-liquid inclusions can be still observed in Figure 11C. This indicates that ultrasound crushing of quartz particles is limited and failed to make smaller gas-liquid inclusions rupture. Figure $11 \mathrm{D}$ shows the polarized micrograph of the sample after calcination pretreatment + ultrasound-assisted acid leaching. It can be clearly seen that the volume of the gas-liquid inclusions is the smallest in this case. During the process of large volume of gas-liquid inclusions burst into small inclusions and consequently the iron impurities released from the inclusions can be dissolved in acid solution, so iron impurities can be further removed.

\section{CONCLUSION}

A harmless purification method of industrially quartz has been proposed. This method, calcination pretreatment combined with ultrasound-assisted by a mixture of oxalic acid and diluted hydrochloric acid leaching, was proven to be an effective way for iron removal from quartz. Under the optimal technological parameters, i.e., a calcination temperature of $900{ }^{\circ} \mathrm{C}$, a calcination holding time of $2 \mathrm{~h}$, a oxalic acid concentration of $10 \mathrm{~g} / \mathrm{L}, \quad$ a hydrochloric acid concentration of $5 \%$, a extraction temperature of $60{ }^{\circ} \mathrm{C}$, a liquid solid ratio of 5 , a ultrasound power of $400 \mathrm{~W}$ and a ultrasound treatment time $30 \mathrm{~min}$, $\mathrm{SiO}_{2}$ content of concentrate increased from $99.6828 \%$ to $99.9047 \%$, and $\mathrm{Fe}_{2} \mathrm{O}_{3}$ content reduced from $0.0857 \%$ to $0.0223 \%$, which achieved $3 \mathrm{~N}$ level high purity quartz. The novel method is more effective than other conventional processes and undesired second pollutions are avoided thus the proposed method is much more environment-friendly than currently known.

\section{REFERENCES}

Balitsky, V.S., Bublikova, T.M., Balitskaya, L.V. and Kalinichev, A.G.: 1996, Growth of high temperature $\beta$-quartz from supercritical aqueous fluids. J. Cryst. Growth, 162, No. 3-4, 142-146. DOI: $10.1016 / 0022-0248(95) 00939-6$

Du, F.H., Li, J.S., Li, X.X. and Zhang, Z.Z.: 2011, Improvement of iron removal from silica sand using ultrasound-assisted oxalic acid. Ultrason. Sonochem., 18, No. 1, 389-393.

DOI: $10.1016 /$ j.ultsonch.2010.07.006

Farmer, A.D., Collings, A.F. and Jameson, G.J.: 2000, Effect of ultrasound on surface cleaning of silica particles. Int. J. Miner. Process., 60, No. 2, 101-113. DOI: 10.1016/S0301-7516(00)00009-0

Huang, H.Q., Li, J.S., Li, X.X. and Zhang, Z.Z.: 2013, Iron removal from extremely fine quartz and its kinetics. Sep. Purif. Technol., 108, 45-50. DOI: 10.1016/j.seppur.2013.01.046 

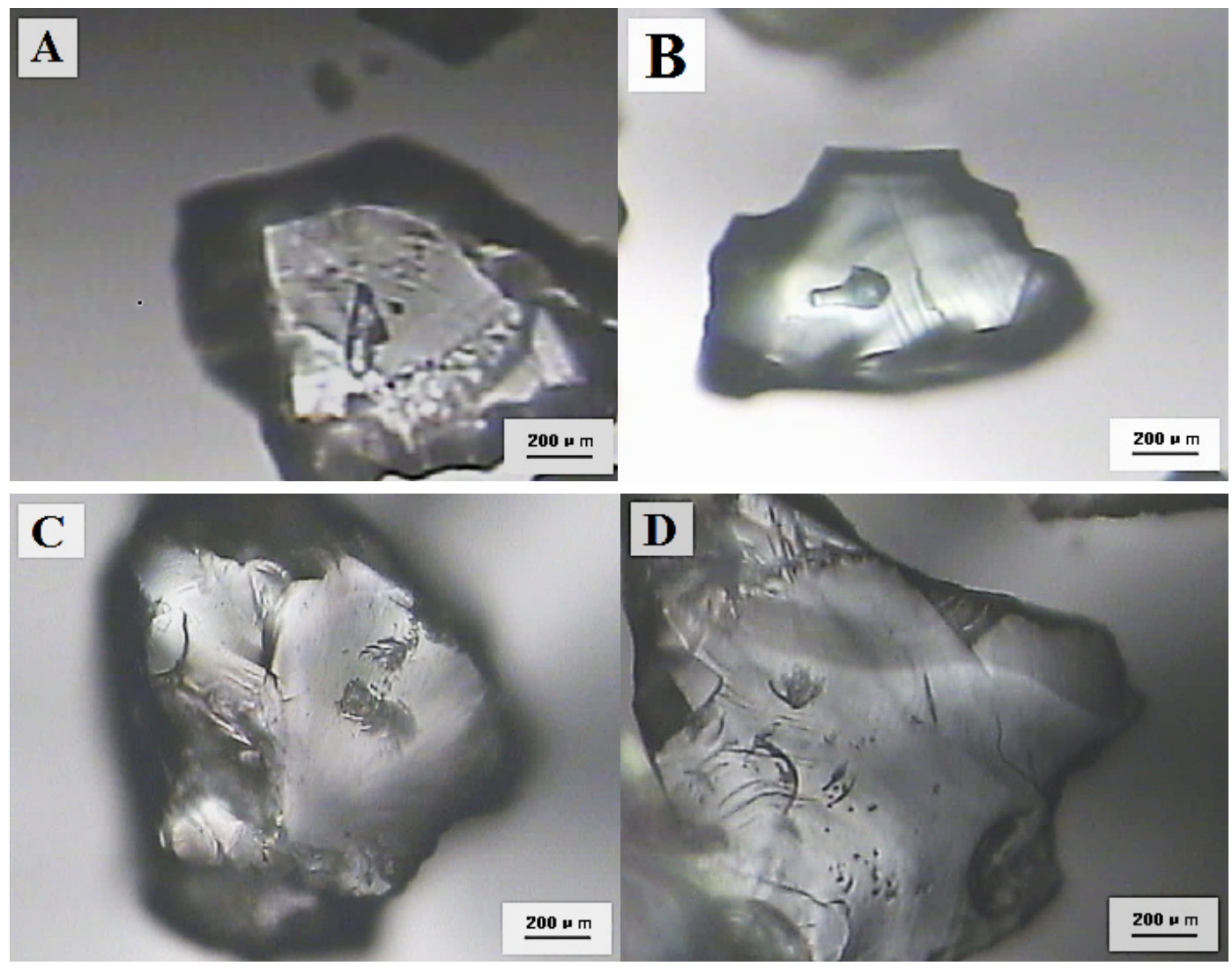

Fig. 11 Polarized light microscope images of (A) Original samples, (B) Leached solid samples, (C) Ultrasound-assisted leached solid samples and (D) Calcination pretreatment + ultrasoundassisted leached solid samples (conditions of samples are same as those described in Fig. 9).

Lee, S.O., Tran, T., Jung, B.H., Kim, S.J. and Kim, M.J.: 2007, Dissolution of iron oxide using oxalic acid. Hydrometallurgy, 87, No. 3-4, 91-99. DOI: $10.1016 /$ j.hydromet.2007.02.005

Li, J.S., Li, X.X., Shen, Q., Zhang, Z.Z. and Du, F.H.: 2010, Further purification of industrial quartz by much milder conditions and a harmless method. Environ. Sci. Technol., 44, No. 19, 7673-7677. DOI: $10.1021 / \mathrm{es} 101104 \mathrm{c}$

Li, X.X., Li, T.H., Gao, J.X., Huang, H.Q., Li, L.B. and Li, J.S.: 2016, A novel "green" solvent to deeply purify quartz sand with high yields: A case study. J. Ind. Eng. Chem., 35, 383-387. DOI: $10.1016 /$ j.jiec.2016.01.018

Moore, G.S.M.: 1993, The $\alpha-\beta$ inversion in submilligram particles of natural quartz. J. Thermal Anal., 40, No. 1, 115-120. DOI: 10.1007/BF02546561

Panias, D., Taxiarchou, M., Paspaliaris, I. and Kontopoulos, A.: 1996, Mechanisms of dissolution of iron oxides in oxalic acid solutions. Hydrometallurgy, 42, No. 2, 257-265. DOI: 10.1016/0304-386X(95)00104-O

Salmimies, R., Mannila, M., Kallas, J. and Häkkinen, A.: 2012, Acidic dissolution of hematite: kinetic and thermodynamic investigations with oxalic acid. Int. J. Miner. Process., 110-111, 121-125. DOI: 10.1016/j.minpro.2012.04.001

Santos, M.F.M., Fujiwara, E., Schenkel, E.A., Enzweiler, L. and Suzuki, C.K.: 2015, Processing of quartz lumps rejected by silicon industry to obtain a raw material for silica glass. Int. J. Miner. Process., 135, 65-70. DOI: $10.1016 /$ j.minpro.2015.02.002
Taxiarchou, M., Panias, D., Douni, I., Paspaliais, I. and Kontopoulos, A.: 1997, Removal of iron from silica sand by leaching with oxalic acid. Hydrometallurgy, 46, No. 1-2, 215-227. DOI: $10.1016 / \mathrm{S} 0304-386 \mathrm{X}(97) 00015-7$

Tuncuk, A. and Akcil, A.: 2014, Removal of iron from quartz ore using different acids: a laboratory-scale reactor study. Min. Proc. Ext. Rev., 35, No. 4, $217-$ 228. DOI: $10.1080 / 08827508.2013 .825614$

Tuncuk, A. and Akcil, A.: 2016, Iron removal in production of purified quartz by hydrometallurgical process. Int. J. Miner. Process., 153, 44-50.

DOI: 10.1016/j.minpro.2016.05.021

Vegliò, F., Passariello, B. and Abbruzzese, C.: 1999, Iron removal process for high-purity silica sands production by oxalic acid leaching. Ind. Eng. Chem. Res., 38, No. 11, 4443-4448. DOI: $10.1021 /$ ie $990156 \mathrm{~b}$

Vegliò, F., Passariello, B., Barbaro, M., Plescia, P. and Marabini, A.M.: 1998, Drum leaching tests in iron removal from quartz using oxalic and sulphuric acids. Int. J. Miner. Process., 54, No. 3-4, 183-200. DOI: 10.1016/S0301-7516(98)00014-3

Zhang, Z.Z., Li, J.S., Li, X.X., Huang, H.Q., Zhou, L.F. and Xiong, T.T.: 2012, High efficiency iron removal from quartz sand using phosphoric acid. Int. J. Miner. Process., 114-117, 30-34. DOI: 10.1016/j.minpro.2012.09.001

Zhao, H.L., Wang, D.X., Cai, Y.X. and Zhang, F.C.: 2007, Removal of iron from silica sand by surface cleaning using power ultrasound. Miner. Eng., 20, No. 8, 816818. DOI: $10.1016 /$ j.mineng.2006.10.005 